\title{
Equine Pyometra: A Case Report
}

\author{
Mohamad Naguib Bin Rais ${ }^{1,2}$, Noraniza Mohd Adzahan², \\ Mimi Armiladiana Mohamad ${ }^{1}$, Lawan Adamu ${ }^{2,3}$ \\ ${ }^{1}$ University Veterinary Teaching Hospital, Universiti Putra Malaysia, 43400 UPM Serdang, Malaysia, \\ ${ }^{2}$ Department of Veterinary Clinical Studies, Faculty of Veterinary Medicine, Universiti Putra Malaysia, 43400 \\ UPM Serdang, Malaysia. ${ }^{3}$ Department of Veterinary Medicine, Faculty of Veterinary Medicine, University of \\ Maiduguri, PMB1069, Borno State, Nigeria
}

\begin{abstract}
Etiopathogenesis of equine pyometra is poorly understood. Diagnosis can be made via physical examination and ultrasonography findings. The recurrence of cases after treatment is high. In the present study, a case of equine pyometra was presented to the University Veterinary Teaching hospital, Universiti Putra Malaysia. On presentation, physical examination and ultrasound finding revealed 'snowy' appearance of the uterus. Uterine flushing was performed and milky creamy exudate was collected using uterine flushing tube. Bacteria isolation and identification showed mix growth of Streptococcus dysagalatiae ss equisimilis and Serratia spp. The systemic antibiotics administered were trimetoprim and sulphadiazine intravenously at the dose rate of $1 \mathrm{ml} / 16 \mathrm{~kg}$ body weight (26ml), SID for 5 day. However, ultrasonography examination after 3 weeks revealed recurrence of the problem.
\end{abstract}

Keyword - Pyometra, Streptococcus dysagalatiae ss equisimili, Ultrasound

\section{Introduction}

Equine pyometra is an accumulation of purulent exudates in the uterus [1]. The etiopathogenesis of equine pyometra is poorly understood. However, poor anus-vulvular conformation, uterine pooling, 'wind sucking', cervical adhesion, abnormally constricted, tortuous or irregular cervix which interferes with the natural drainage are the common factors engrossed in the progression of equine pyometra [2]. In chronic endometritis associated with pyometra, there are few infectious agents being isolated such as Streptococcus zooepidemicus, Escherichia coli, Pseudomonas aeruginosa, Klebsiella pneumonia and Aspergillus spp [1,3].

\section{Case presentation}

A mare was reported to have escaped from the stable and was suspected to mate with a stallion four month before it was presented to a veterinarian. First examination planned for pregnancy diagnosis was based on the history and progressive increase in abdominal size as shown in (Fig. 1). Rectal temperature was found to be $37.2{ }^{\circ} \mathrm{C}$ and heart rate was 32 beats per minute. The appetite and demeanor were good, and clinically it does not show any systemic problem.

\section{Clinical examination, diagnostic work-up and treatment}

At first presentation, physical appearance of the mare showed significantly increased size of the abdomen as compared to active working horses. Gross examination of equine anal and vulvular region indicated $1 / 3$ of vulva slopes forward as shown in (Fig. 3). The anus and vulva were not vertically aligned while the anus was depressed cranially and was positive for wind sucking test (Fig. 2 and Fig. 3). It was not on estrus and no discharges were observed at perivulvular region. Rectal palpation revealed 'doughy' solid feel of the uterus. Ultrasonographic examination showed 'snowy' appearance of the uterus and thickening of the uterine wall [4]. (Fig. 4).

Two days before the uterine flushing, $1 \mathrm{ml}$ of Cloprostenol (Estrumate ${ }^{\circledR}$ ) was administered intramuscularly in order to induce relaxation of the cervix. Before proceeding with uterine flushing, ultrasound re-examination revealed similar finding like the one observed on the first visit. The mare was sedated using 0.7 $\mathrm{ml}$ of detomidine; $0.01 \mathrm{mg} / \mathrm{kg}$ intravenously under sterile condition. Uterine flushing tube (EQUIVET) was inserted into the uterus via the cervix. Milky creamy exudate was collected through the tube and sent to the laboratory for bacteria and fungus isolation and identification as well as cytology examination. Immediately, $2 \mathrm{~L}$ of $0.9 \% \mathrm{NaCl}$ was irrigated into the uterus via the tube and uterine lavage was performed by means of gravity flow. Besides, whole blood and serum sample were also collected for hematology and serum biochemistry examination.

As prophylaxis, $26 \mathrm{ml}$ of gentamicin at the dose rate of $1 \mathrm{ml} / 16 \mathrm{~kg}$ body weight was administered intramuscularly SID for 5 days. Flunixin meglumine, $10 \mathrm{ml}, 1.1 \mathrm{mg} / \mathrm{kg}$ was administered intravenously in order to prevent inflammation due to manipulation of rectum and uterus during the procedure. In addition, an ecbolic 
$2.5 \mathrm{ml}$ of oxytocin, $20 \mathrm{IU}$, SID was administered intramuscularly in order to induce uterine contraction to enhance the evacuation of uterine content.

Isolation of the bacteria showed mix growth of Streptococcus dysagalatiae ss equisimilis and Serratia spp. However, the results of the hematology and serum biochemistry findings were not significant. Cytology result showed large amounts of calcium carbonates in the sample. This might indicate possible contamination of the sample by urine.
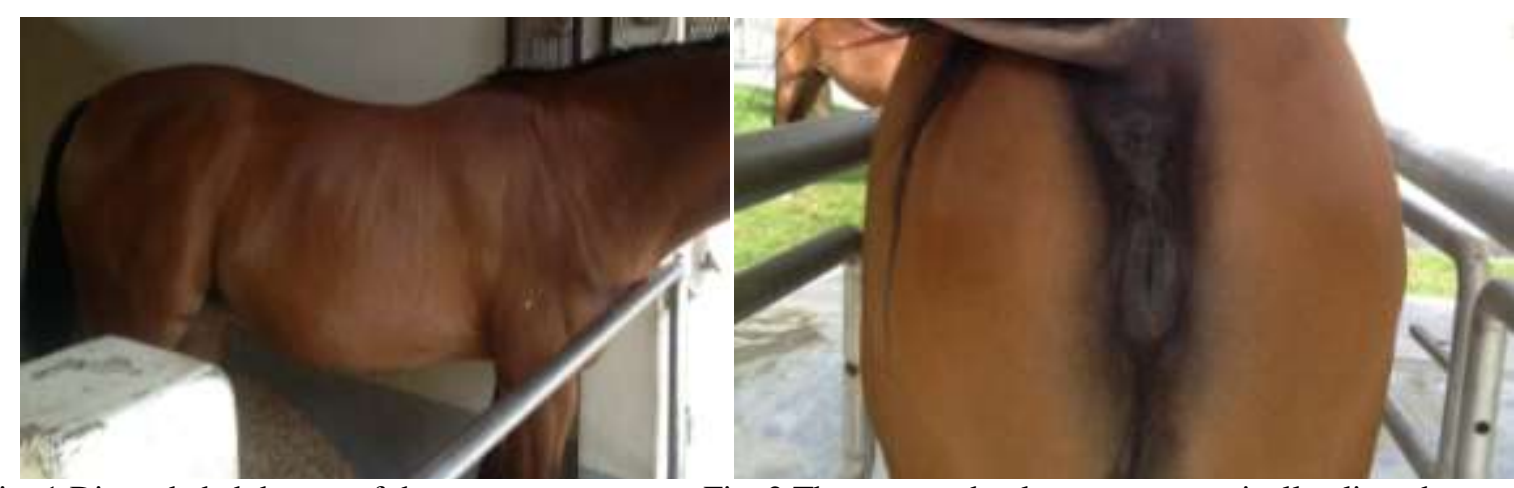

Fig. 1 Distended abdomen of the mare

Fig. 2 The anus and vulva was not vertically aligned

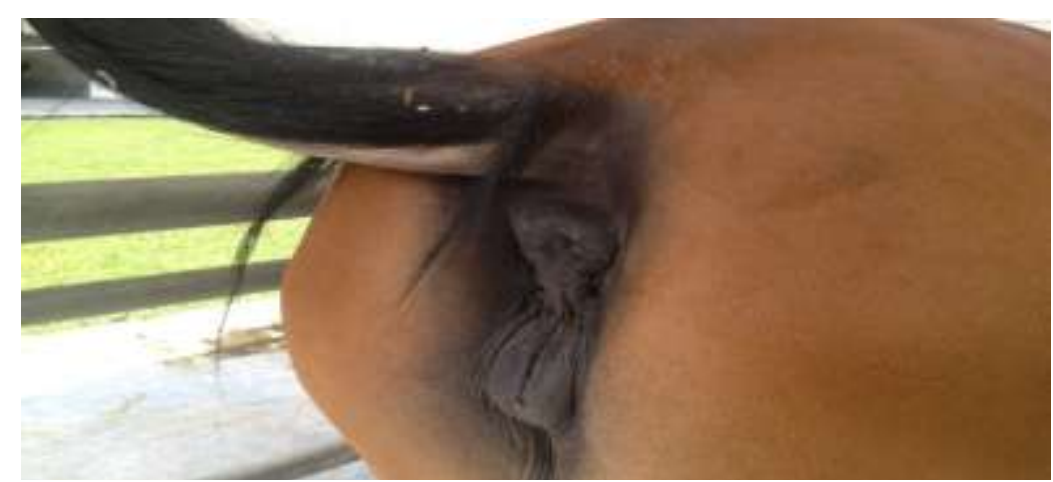

Fig. 3 The anus sunken cranially, 1/3 of vulva slopes forward and positive for wind sucking test

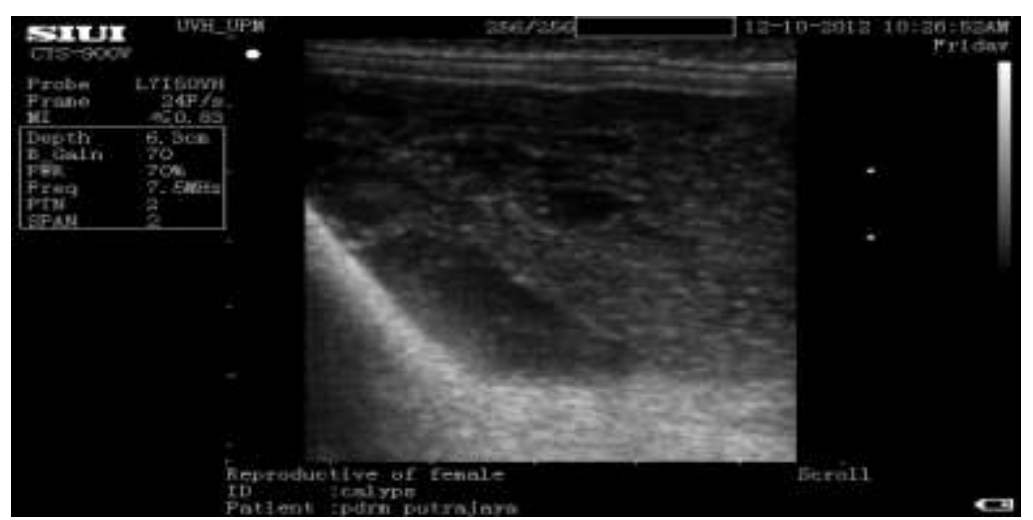

Fig. 4 'Snowy' appearances of the uterus and thickening of the uterine wall

\section{Discussion}

Equine pyometra can be considered as pseudo pregnancy which has tremendous economic impact to the breeder. Selection of mare for breeding is important in order to avoid time wasting and loss of money. The mare reproductive tract has three natural mechanisms for the protection of the vulva seal, vestibulovagina seal and closure of the cervix [5]. Any defect on one of these mechanisms leads to reproductive abnormality.

Poor confirmation of the mare external genitalia can be a predisposing factor for the occurrence of pyometra [3]. In the present case study, the mare had poor anal to vulvular conformation as the anus was sunken cranially and was not vertically aligned with the vulva. The fecal material can be trapped at the ventral fissure of the vulva, thus leading to ascending infection. This condition may be associated with vaginitis. However, there is no abnormal finding of the vagina mucosa in this case study. Besides that, weak vulva labia were due to poor 
conformation and were the reasons for the occurrence of wind sucking [3]. Wind sucking leads to pneumovagina hence, in this condition air contains microbes or dust trapped in the vagina thus, predisposing it to vaginitis, cervicitis or endometritis especially during estrous $[1,3]$. Besides, influx of air can interrupt the vestibulovagina fold thus, leading to urine pooling [2]. At this stage, wind sucking test was able to identify mare that had chances of acquiring pneumovagina as indicated in the present case study.

Vaginascopy has the ability of identifying accumulation of dirty materials, dust or fecal materials trapped in the vagina. Furthermore, this procedure is also able to identify urine pooling due to defects in vestibulovagina seal or poor confirmation of the cervix [5]. Vaginascopy is a reliable confirmatory method of pneumovagina. Nonetheless, it was not performed in this case study due to limitation of equipment to perform the procedure in the field.

In the present case study, cytology examination showed numerous calcium carbonates in the sample. There are only two reasons for the presence of calcium carbonates in the sample which was either due to the contamination of the sample by the urine during per vagina insertion of the tube, or due to the presence of the urine in uterus as a result of urine pooling in the vagina which may be the cause of pyometra and endometritis. Isolation of Streptococcus dysagalatiae ss equisimilis and Serratia spp from the sample indicated a high possibility of the occurrence of pyometra in the present case study which was due to pneumovagina with concurrent contamination of the uterus by the urine. Streptococcus dysagalatiae ss equisimilis and Serratia spp were opportunistic bacteria which are commonly isolated from vagina and urinary tract similarly; in the present case study they were isolated from the sample collected directly from the uterus [6-7]. Even though, vaginascopy was not perform, the presence of calcium carbonates and the bacteria isolated from the sample can be an evidence of contamination of the uterus by the urine which subsequently leads to pyometra and endometritis. Besides, the procedure was performed under sterile condition in order to prevent any possible chances of contamination. There is no doubt that vaginascopy is vital procedure and it was not performed in the present case study in order to strengthen the findings. Without the use of vaginascopy, there is no chance of ruling out pyometra as a result cervical defect.

The prognosis of pseudo pregnancy cases particularly, pyometra, mucometra or hydrometra only can be determined via uterine biopsy [5]. Neither systemic nor intrauterine antimicrobial therapy is proven to resolve these problems. However, immediate mating after uterine flushing with antibiotics is an option to breed mare with the history of reproductive abnormalities [1].

\section{Conclusion}

Pyometra in mare is highly associated with poor conformation of the vulva. It is imperative for individual horse owners to identify the suitability of their horse for breeding. Limitation of equipment especially in field is a main constraint for the performance of thorough examination of the reproductive system of the mare.

\section{Acknowledgement}

The clinicians appreciate the effort and assistance offered by Drs. Dayang and Shima of Veterinary Teaching Hospital, Universiti Putra Malaysia, for their assistance, advice, and encouragement.

\section{References}

[1] J.C. Samper, J.F. Pycock, A.O. McKinnon, Current Therapy in Equine Reproduction (St. Louis, Missouri: Saunders, 2007,

[2] D.C Knottenbelt, M.L. Blanc, C. Lopate, R.R. Pascoe, Equine Stud Farm Medicine and Surgery (Edinburgh, UK: Elsevier Science Ltd, 2003,

[3] G.C.W. England, Fertility and Obstetrics in the Horse, $3^{\text {rd }}$ Edition, (Oxford, UK: Blackwell Publishing Ltd, 2005,

[4] K. Wolfgang, Veterinary Reproductive Ultrasonography (Hannover, Germany: Schl $\square$ tersche Verlagsgesellschaft mbH, 2004,

[5] S.P. Brincko, T.L Blanchard, D.D. Varner, J. Schumacher, C.C. Love, K. Hinrichs, K. Hartman, Manual of Equine Reproduction (Maryland Heights, Missouri: Mosby Elsevier, 2011,

[6] M. McDonald, R.J. Towers, R.M Andrews, J.R. Carapetis., G.J. Currie, Epidemiology of Stretococcus Dysagalactiae subsp. Equisimilis, Emerging Infectious Disease, 13(11), 2007, 1694-1700

[7] J.F. Timoney, The Pathogenic Equine Streptococci, Veterinary Research, 35, (4), 2004, 397-409

[8] S. Preziuso, F. Laus, A.R. Tejeda, C. Valente, V. Cuteri, Detection of Stretococcus Dysagalactiae subsp. equisimilis in Equine Nasopharyngeal swabs by PCR, Journal of Veterinary Science, 11,(1), 2010, 67-72 